\title{
Response to Systemic Corticosteroids on Persistently High Exhaled Nitric Oxide in Severe Asthma
}

Tsunahiko Hirano, Kosuke Ito, Nobutaka Edakuni and Kazuto Matsunaga*

Division of Respiratory Medicine and Infectious Disease, Graduate School of Medicine, Yamaguchi University, Japan

${ }^{*}$ Corresponding author: Matsunaga K, Division of Respiratory Medicine and Infectious Disease, Graduate School of Medicine, Yamaguchi University, 1-1-1 Minamikogushi, Ube, 755-8505, Japan, Tel: +81-836-85-3123, Fax: +81-836-85-3124; E-mail: kazmatsu@yamaguchi-u.ac.jp

Received date: July 13, 2015; Accepted date: August 19, 2015; Published date: August 25, 2015

Copyright: @ 2015 Hirano T, et al. This is an open-access article distributed under the terms of the Creative Commons Attribution License, which permits unrestricted use, distribution, and reproduction in any medium, provided the original author and source are credited.

\section{Short Communication}

Nitric oxide (NO), a gaseous signaling molecule generated by $\mathrm{NO}$ synthase (NOS), is enhanced by inflammatory stimuli [1]. The exhaled nitric oxide fraction (FeNO) has been proposed as a marker of airway inflammation and a guide for anti-inflammatory therapy in asthma [1]. However, a persistently high FeNO is occasionally observed despite inhaled corticosteroids (ICS) therapy [2-4]. Excessive NO synthesis is well documented in severe asthma [5,6]. Also, it is suggested that some proportion of individuals are truly steroid resistant, which is defined as no clinical improvement after treatment with systemic steroids [7]. However, few studies have provided detailed data regarding the variability of change in FeNO by administration of systemic steroids and its impact on asthma control and lung function in patients with severe asthma and persistently high FeNO.

This prospective study was undertaken to assess the predictors for identifying the efficacy of systemic steroids on residual FeNO elevations in patients with severe asthma. The main results of the study have been reported previously [8]. The FeNO levels and blood eosinophil numbers were independently associated with an improved residual airway inflammation. In the present study, we assessed the variability of changes in FeNO through administration of systemic corticosteroids and correlated these changes with asthma control, lung function, and blood eosinophil numbers.

The characteristics of the present cohort have been published previously [8]. Twenty patients with severe asthma and sustained high FeNO despite maintenance therapy including high-daily-dose ICS were surveyed. Asthma Control Questionnaire (ACQ), lung function, blood eosinophil numbers, and FeNO were measured before and after 14 days treatment with $0.5 \mathrm{mg} / \mathrm{kg}$ oral prednisolone/day. Informed consent was obtained from all patients. The criterion for refractory asthma from the ATS was used to determine the severity classifications [9]. Subjects were excluded if they were current smokers, had an exacerbation of asthma within 8 weeks prior to the survey. Also, patients with poor adherence to the therapy or with other pulmonary diseases were excluded. The study was approved by the local ethics committee (IRB \#526). FeNO was measured by a chemiluminescence NO analyzer [8]. Based on our previous studies [3,10], we selected 40 ppb as the cutoff point for high and low FeNO. The forced vital capacity (FVC), forced expiratory volume in $1 \mathrm{~s}\left(\mathrm{FEV}_{1}\right)$, and blood eosinophil numbers were measured as previously described [8]. The measurements at different time points were compared by Wilcoxon signed rank test. Receiver operating curve (ROC) was used to determine a cut-off point for the change in FeNO that would identify patients with $\mathrm{a} \geq 200 \mathrm{~mL}$ increase in $\mathrm{FEV}_{1}$. A p-value of $<0.05$ was considered significant.

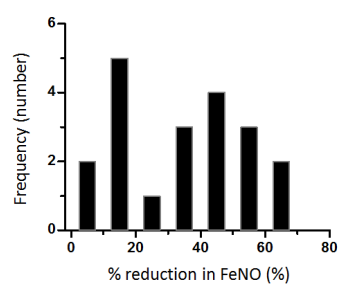

Figure 1: Distribution of changes in exhaled nitric oxide fraction (FeNO) through administration of systemic corticosteroids in patients with severe asthma. Each bar represents reduction in FeNO of $10 \%$.

The distribution of changes in FeNO level was shown in Figure 1. The mean change in FeNO was a reduction of $34.0 \%$, with significant variation in the levels of change. The between patient standard deviation for the rate of reduction was $19.5 \%$. ROC analysis showed that a reduction in FeNO of $\geq 31.7 \%$ yielded $100 \%$ sensitivity and $70 \%$ specificity for identifying patients with $\mathrm{a} \geq 200 \mathrm{ml}$ increase in $\mathrm{FEV}_{1}$ (AUC=0.91) (Figure 2). Based on the magnitude of reduction in FeNO, we labeled those of greater than the $30 \%$ as steroid responders $(n=12)$, and less than the $30 \%$ as steroid poor-responders $(n=7)$.

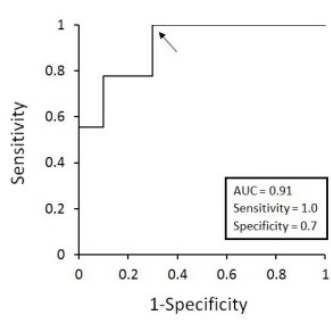

Figure 2: Receiver operating characteristics (ROC) curve to estimate the cutoff values of \% change in FeNO for identifying patients with $\mathrm{a} \geq 200 \mathrm{ml}$ increase in forced expiratory volume in 1 second (FEV1). Data labels represent cutoff values of $\%$ change in FeNO (arrow), area under the curve (AUC), sensitivity and specificity.

At baseline, there was no significant difference in age, gender, body mass index, asthma treatment, ACQ score, \%FVC, and \% $\mathrm{FEV}_{1}$ between the two groups. As shown in Figure 3, the steroid-mediated reduction in FeNO of greater than $30 \%$ was significantly associated 
with improvements in ACQ and $\mathrm{FEV}_{1}($ all $\mathrm{p}<0.05)$ but not with change in blood eosinophil numbers $(\mathrm{p}=0.19)$. Minimal clinical important difference in ACQ score ( $\geq 0.5$ decrease) was observed in 8 of steroid responders (67\%) and 1 of steroid poor-responders (14\%). A total of 9 patients showed $\geq 200 \mathrm{ml}$ increase in $\mathrm{FEV}_{1}$, and all cases were steroid responders.

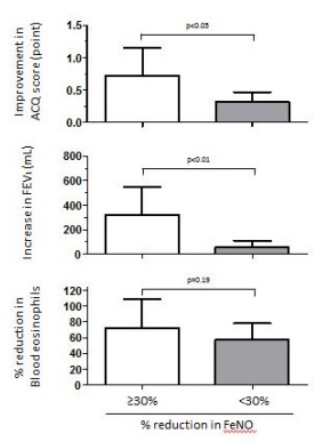

Figure 3: Changes in Asthma Control Questionnaire (ACQ) score, forced expiratory volume in 1 second (FEV1), and blood eosinophil numbers according to the magnitude of reduction in FeNO (\%). The error bars represent standard deviations.

The present study has shown that the change in FeNO through administration of systemic corticosteroids is highly variable, and the FeNO in approximately $40 \%$ of the study subjects was not reduced greater than $30 \%$. These data suggest that truly steroid-resistant inflammatory processes in the airways are involved in the sustained high levels of FeNO in patients with severe asthma. Several distinct mechanisms that contribute to decreased anti-inflammatory effects of steroids have now been identified [11]. These include steroid receptor modification, abnormal histone acetylation, increased glucocorticoid receptor- $\beta$ expression, and constitutive NOS sources. Moreover, corticosteroids may induce epigenetic modification on the FeNO level. DNA methylation is increasingly proposed as a mechanism for underlying asthma-related inflammation, and FeNO increased in association with lower promoter methylation of both IL-6 and iNOS [12]. Recent evidence shows that the up-regulation of iNOS in the airways via STAT-6 and Th2-cytokines interleukin (IL)-4 and IL-13, produces enhanced NO concentrations in exhaled air [13]. However, persistently high FeNO have also been observed in association with elevations of concomitant Th1 cytokines [13,14]. IL-4 and IL-13 in combination with IFN- $\gamma$ synergistically enhance iNOS expression [14]. The mixed Th1/Th2 characteristics may be involved in the steroid unresponsiveness in asthma [14-17]. The IFN- $\gamma$-mediated iNOS expression is virtually steroid resistant, as evidenced both in vitro [16] and in vivo [17]. In addition, recent studies have suggested that persistently high FeNO could be also due to the heritable nature of FeNO on a family related basis $[18,19]$.

Recent evidence suggests that the residual airway inflammation detected by FeNO is an important therapeutic target in asthma. The large cross-sectional analyses demonstrated that the grouping of asthma by $\mathrm{FeNO}$ provides an independent classification of asthma severity, and the subgroups with sustained high FeNO tend to be a highly reactive asthma phenotype [2,3]. Moreover, in the same group of patients, we have previously reported that the reduction in FeNO levels was significantly correlated with the improvements in ACQ,
FVC, and $\mathrm{FEV}_{1}$ by systemic steroid therapy [8]. The present study expands on these data. The reduction in FeNO of $\geq 30 \%$ was corresponded with the improvements in ACQ and FEV ${ }_{1}$. Recently, the efficacy of dupilumab, a human monoclonal antibody to the $\alpha$-subunit of the IL-4 receptor, in patients with moderate-to-severe asthma was evaluated [20]. The dupilumab therapy was associated with fewer asthma exacerbations and with improved lung function. The degree of reduction in the FeNO level was correlated with the improvement in FEV1. By contrast, blood eosinophil levels were unchanged with dupilumab [20]. These findings are consistent with the current observations. The clinical improvements on top of ICS/LABA suggested that high-daily-dose ICS had not completely suppressed the IL-4 and IL-13-mediated immune process in these severe patients with residual airway inflammation. However, the blood eosinophilia associated with this phenotype does not appear to be controlled by IL-4 or IL-13. Although, it has been associated with eosinophilic inflammation, selective reduction in blood and sputum eosinophils following anti-IL-5 targeted therapy does not decrease FeNO level [21], supporting important differences between these Th2 cytokine associated biomarkers. Further studies are required to investigate the mechanisms of persistent FeNO elevation including patient's molecular profile.

In conclusion, this prospective study provided evidence that the change in FeNO level through administration of systemic corticosteroids is highly variable, and the reduction in FeNO levels is associated with improvement in asthma control and lung function in patients with severe asthma and sustained high FeNO.

\section{Acknowledgements}

This work was supported by grant H24-Kibankenkyu (C)-22591057 from the Japanese Society for the Promotion of Science.

\section{Competing interests}

No potential conflicts of interest existed with any companies or organizations whose products or services may have been discussed in this article.

\section{References}

1. Dweik RA, Boggs PB, Erzurum SC, Irvin CG, Leigh MW, et al. (2011) An official ATS clinical practice guideline: interpretation of exhaled nitric oxide levels (FENO) for clinical applications. Am J Respir Crit Care Med 184: 602-615.

2. Dweik RA, Sorkness RL, Wenzel S, Hammel J, Curran-Everett D, et al. (2010) Use of exhaled nitric oxide measurement to identify a reactive, atrisk phenotype among patients with asthma. Am J Respir Crit Care Med 181: 1033-1041.

3. Matsunaga K, Yanagisawa S, Hirano T, Ichikawa T, Koarai A, et al. (2012) Associated demographics of persistent exhaled nitric oxide elevation in treated asthmatics. Clin Exp Allergy 42: 775-781.

4. Hirano T, Matsunaga K, Sugiura H, Minakata Y, Koarai A, et al. (2013) Persistent elevation of exhaled nitric oxide and modification of corticosteroid therapy in asthma. Respir Investig 51: 84-91.

5. Sugiura H, Komaki Y, Koarai A, Ichinose M (2008) Nitrative stress in refractory asthma. J Allergy Clin Immunol 121: 355-360.

6. Amelink M, de Groot JC, de Nijs SB, Lutter R, Zwinderman AH, et al. (2013) Severe adult-onset asthma: A distinct phenotype. J Allergy Clin Immunol 132: 336-341.

7. Barnes PJ, Greening AP, Crompton GK (1995) Glucocorticoid resistance in asthma. Am J Respir Crit Care Med 152: S125-140. 
Citation: Hirano T, Ito K, Edakuni N, Matsunaga K (2015) Response to Systemic Corticosteroids on Persistently High Exhaled Nitric Oxide in Severe Asthma. J Allergy Ther 6: 219. doi:10.4172/2155-6121.1000219

Page 3 of 3

8. Matsunaga K, Hirano T, Akamatsu K, Minakata Y (2013) Predictors for identifying the efficacy of systemic steroids on sustained exhaled nitric oxide elevation in severe asthma. Allergol Int 62: 359-365.

9. [No authors listed] (2000) Proceedings of the ATS workshop on refractory asthma: current understanding, recommendations, and unanswered questions. American Thoracic Society. Am J Respir Crit Care Med 162: 2341-2351.

10. Hayata A, Matsunaga K, Hirano T, Akamatsu K, Ichikawa T, et al. (2013) Stratifying a risk for an increased variation of airway caliber among the clinically stable asthma. Allergol Int 62: 343-349.

11. Barnes PJ, Adcock IM (2009) Glucocorticoid resistance in inflammatory diseases. Lancet 373: 1905-1917.

12. Baccarelli A, Rusconi F, Bollati V, Catelan D, Accetta G, et al. (2012) Nasal cell DNA methylation, inflammation, lung function and wheezing in children with asthma. Epigenomics 4: 91-100.

13. Alving K, Malinovschi A (2010) Basic aspects of exhaled nitric oxide. Eur Respir Mon 49: 1-31.

14. Ray A, Oriss TB, Wenzel SE (2015) Emerging molecular phenotypes of asthma. Am J Physiol Lung Cell Mol Physiol 308: L130-140.

15. Voraphani N, Gladwin MT, Contreras AU, Kaminski N, Tedrow JR, et al. (2014) An airway epithelial iNOS-DUOX2-thyroid peroxidase metabolome drives Th1/Th2 nitrative stress in human severe asthma. Mucosal Immunol 7: 1175-1185.

16. Donnelly LE, Barnes PJ (2002) Expression and regulation of inducible nitric oxide synthase from human primary airway epithelial cells. Am J Respir Cell Mol Biol 26: 144-151.

17. Lundberg JO, Weitzberg E, Rinder J, Rudehill A, Jansson O, et al. (1996) Calcium-independent and steroid-resistant nitric oxide synthase activity in human paranasal sinus mucosa. Eur Respir J 9: 1344-1347.

18. Lund MB, Kongerud J, Nystad W, Boe J, Harris JR (2007) Genetic and environmental effects on exhaled nitric oxide and airway responsiveness in a population-based sample of twins. Eur Respir J 29: 292-298.

19. Tarnoki DL, Tarnoki AD, Medda E, Littvay L, Lazar Z, et al. (2013) Genetic influence on the relation between exhaled nitric oxide and pulse wave reflection. J Breath Res 7: 026008.

20. Wenzel S, Ford L, Pearlman D, Spector S, Sher L, et al. (2013) Dupilumab in persistent asthma with elevated eosinophil levels. N Engl J Med 368: 2455-2466.

21. Pavord ID, Korn S, Howarth P, Bleecker ER, Buhl R, et al. (2012) Mepolizumab for severe eosinophilic asthma (DREAM): a multicentre, double-blind, placebo-controlled trial. Lancet 380: 651-659. 